\title{
Immune response of cows fed polyunsaturated fatty acids under high ambient temperatures
}

\author{
M. Caroprese, ${ }^{* 1}$ A. Marzano, ${ }^{*}$ G. Entrican, $\dagger$ S. Wattegedera,† M. Albenzio, ${ }^{*}$ and A. Sevi* \\ *Dipartimento PRIME and Istituto per la Ricerca e le Applicazioni Biotecnologiche per la Sicurezza e la Valorizzazione dei Prodotti \\ Tipici e di Qualità (BIOAGROMED), Università di Foggia, Via Napoli 25, 71100 Foggia, Italy \\ †Moredun Research Institute, Pentlands Science Park, Bush Loan, Midlothian, EH26 OPZ, United Kingdom
}

\section{ABSTRACT}

The aim of the experiment was to determine the effects of 2 different fat supplementations on immune functions of dairy cows under high ambient temperatures. The experiment involved 24 Italian Friesian cows, divided into 3 groups of 8 animals, that were subjected to fat supplementations based on whole flaxseed (FS) or microencapsulated fish oil (FO). At d 0, 45, and 90 of the experiment, lymphocyte response to phytohemagglutinin (PHA) was determined in vivo on each animal by measurement of skin-fold thickness at the site of PHA injection. A humoral response to chicken egg albumin (OVA) was established following a subcutaneous injection with OVA. To assess cows' immune responses, plasma was prepared from experimental blood samples taken at d 0, 15, 30, 45, 60, 75, and 90 of the experiment. Plasma samples were measured for the presence of anti-OVA IgG, IL-1 $\beta$, IL-6, and IL10. Results revealed greater skin-fold thickness in cows fed FS compared with the FO and the control groups, corresponding to higher mean lymphocyte proliferation following in vivo PHA injection. Cows fed FS displayed higher titers of anti-OVA IgG than the control and FOfed cows. No effects of the diet on IL- $1 \beta$ or IL- 6 were found, whereas IL-10 secretion was lower in FS-fed cows than in control cows. The present study demonstrates that feed supplementation of n-3 polyunsaturated fatty acids can enhance immune responses of dairy cows exposed to high ambient temperatures.

Key words: immune function, dairy cow, polyunsaturated fatty acid, high ambient temperature

\section{INTRODUCTION}

Environmental and nutritional factors such as ambient temperature and diet have been implicated in alterations of immune function. Peripheral blood mononuclear cells (PBMC) collected from dairy cattle experiencing

Received October 15, 2008.

Accepted February 15, 2009.

${ }^{1}$ Corresponding author: m.caroprese@unifg.it temperature-humidity index (THI) values $>72$ exhibit reduced proliferation in vitro in response to mitogenic stimulation compared with PBMC from cattle experiencing THI values $<72$ (Lacetera et al., 2005). Furthermore, incubation of cattle PBMC at high temperature $\left(42^{\circ} \mathrm{C}\right)$ reduces proliferation to mitogens compared with incubation at $38.5^{\circ} \mathrm{C}$, an observation that is not simply due to reduced cell viability (Elvinger et al., 1991). The precise mechanisms underlying reduced cellular immune function in cattle under higher temperatures remain undefined, particularly with regard to cytokine profiles that would be indicative of a regulatory, antiinflammatory phenotype.

A balanced and adequate diet positively influences the development, maintenance, and function of the immune system. Several studies in humans have reported that increased intake of n-3 polyunsaturated fatty acids (PUFA) in plant and fish oils results in decreased proliferation of PBMC in response to mitogenic stimulation and decreased production of proinflammatory cytokines such as IL-1 $\beta$, IL-6, and tumor necrosis factor (TNF)- $\alpha$ (Kelley, 2001). Such immunomodulatory effects have led to an interest in the therapeutic use of dietary PUFA to treat inflammatory immune disorders in humans (Calder, 2002). Consistent with the studies in humans, PUFA have also been reported to exert immunomodulatory effects in livestock. Dairy cows fed flaxseed rich in n-3 PUFA exhibit a transient reduction in mitogen-driven PBMC and a reduction in blood concentration of prostaglandin $\mathrm{E}_{2}$ after calving (Lessard et al., 2003). The immunomodulatory effects of n-3 PUFA in cattle appear to be directed more toward T-cell and monocyte/macrophage function because there are no significant differences in antigen-specific antibody responses in cattle fed flaxseed compared with cattle fed a diet enriched with saturated fatty acids or soybeans (n-6 PUFA; Lessard et al., 2003, 2004). The infusion of fish oil or linseed to PBMC isolated from fasted dairy cows contributed to reduce the alteration of lymphocytes to mitogens (Lacetera et al., 2007).

The aim of the present study was to evaluate the effects of dietary fatty acid enrichment (flaxseed and fish 
Table 1. Ingredient and chemical composition of the experimental diets (DM basis)

\begin{tabular}{lccc}
\hline & \multicolumn{3}{c}{ Diet $^{1}$} \\
\cline { 2 - 4 } Item & Control & FO & FS \\
\hline Ingredient & & & \\
Concentrate & 61.4 & 60.7 & 54.8 \\
Corn & 5.7 & 5.7 & 5.7 \\
Oat hay & 32.9 & 32.5 & 33 \\
Whole flaxseed & 0 & 0 & 6.5 \\
Fish oil & & 1.1 & 0 \\
Chemical composition & 0 & 92.00 & 92.26 \\
DM, \% & 92.04 & 3.46 & 5.31 \\
Ether extract, \% of DM & 3.23 & 15.36 & 15.21 \\
CP, \% of DM & 15.43 & 22.49 & 22.75 \\
ADF, \% of DM & 22.72 & 41.45 & 40.84 \\
NDF, \% of DM & 40.99 & 3.95 & 4.09 \\
ADL, \% of DM & 3.98 & 1.69 & 1.65 \\
NE, Mcal/kg & 1.68 & & \\
\hline
\end{tabular}

${ }^{1}$ Control group had no fat supplementation; FO = group with fat supplementation based on fish oil; FS = group with fat supplementation based on flaxseed.

${ }^{2}$ Lin Tech (Tecnozoo srl, Torreselle di Piombino Dese, Italy).

${ }^{3}$ Orovital Cod (Ascor Chimici srl, Capocolle di Bertinoro, Italy).

${ }^{4} \mathrm{ADL}=$ acid detergent lignin.

oil) on the immune function of dairy cows experiencing high ambient temperatures.

\section{MATERIALS AND METHODS}

\section{Animals and Monitoring of Environmental Conditions}

The experimental site was a commercial farm located approximately $20 \mathrm{~km}$ northeast of Foggia, Apulia, southern Italy (latitude $41^{\circ} 27^{\prime} 6^{\prime \prime}$ and longitude $15^{\circ} 33^{\prime} 5^{\prime \prime}$ ). Air temperature and relative humidity were monitored daily using TIG2-TH thermo-hygrographs (LSI, Settala Premenugo, Milan, Italy). Data from thermo-hygrographs in conjunction with Kelly and Bond's (1971) formula were used to calculate the THI. The 12 -wk trial was performed from June to September 2006, with 24 Italian Friesian cows divided into 3 groups of 8 cattle. The cows were blocked based on age, BW, DIM (100.11 \pm 3.79 ), parity $(2.46 \pm 0.26)$, milk yield $(24.37 \pm 0.36$ $\mathrm{kg} / \mathrm{d})$, and milk fat $(3.77 \pm 0.13)$, and protein $(3.03 \pm$ 0.08) content.

\section{Experimental Diets and Chromatographic Analysis of Feed}

All animals were individually fed with the same diet based on corn silage, oat hay, and concentrate, plus different fat supplementations based on whole flaxseed (FS; Lin Tech, Tecnozoo srl, Torreselle di Piombino Dese, Italy) or microencapsulated fish oil (FO; Orovital Cod, Ascor Chimici srl, Capocolle di Bertinoro, Italy)
(Table 1). Cows were fed twice daily and feed consumption was recorded daily. Cows in all groups completely consumed the daily ration given. The DMI was 16.57 $\mathrm{kg} / \mathrm{d}$ for control cows, $16.75 \mathrm{~kg} / \mathrm{d}$ for FO cows, and $16.61 \mathrm{~kg} / \mathrm{d}$ for FS cows. Net energy for lactation was calculated using NRC (2001). Water was available ad libitum. A sample from each experimental diet was taken weekly, frozen, and mixed for chemical analyses. The chemical composition of diets was determined by standard procedures (AOAC, 1990; Table1). Fatty acid analysis of supplementations was carried out according to Sukhija and Palmquist (1988). Fatty acid methyl esters (FAME) were analyzed on an Agilent $6890 \mathrm{~N}$ gas chromatograph (Agilent, Santa Clara, CA). Separation of the FAME was performed using a DB 23 fused-silica capillary column $[60 \mathrm{~m} \times 0.25 \mathrm{~mm}$ (i.d.) with $0.25 \mu \mathrm{m}$ film thickness]. Operating conditions were helium flow rate of $1.2 \mathrm{~mL} / \mathrm{min}$; flame-ionization detector at $250^{\circ} \mathrm{C}$; a split-splitless injector at $240^{\circ} \mathrm{C}$; and an injection volume of $1 \mu \mathrm{L}$ with a split ratio 1:50. The initial column temperature was set at $60^{\circ} \mathrm{C}$, increased to $180^{\circ} \mathrm{C}$ at $25^{\circ} \mathrm{C} / \mathrm{min}$, and finally increased to $230^{\circ} \mathrm{C}$ at $6^{\circ} \mathrm{C} /$ min and held for $15 \mathrm{~min}$. Retention time and area of each peak were computed using the 6890N NETWORK GC system software (Agilent). Individual FAME peaks were identified by comparing their retention times with those of defined standards (FAME mix 37 components; Matreya, Sigma-Aldrich, Milan, Italy). Results were expressed as percentage of total fatty acids analyzed (Table2).

\section{Evaluation of the Cell-Mediated Immune Response}

At d 0, 45, and 90, lymphocyte proliferation was determined in vivo in each cow by the measurement of changes in skin-fold thickness in response to intradermal injection with $1 \mathrm{mg} / \mathrm{mL}$ of phytohemagglutinin (PHA; Sigma) dissolved in $1 \mathrm{~mL}$ of sterile saline solution. At each sampling time, the injection was administered into the center of a 2-cm-diameter circle marked on shaved skin on the upper side of each shoulder. The determination of lymphocyte proliferation, measured as skin-fold

Table 2. Fatty acid composition (\% of total fatty acids) of fat supplementations

\begin{tabular}{lcc}
\hline Fatty acids, \% of total of fatty acids & Flaxseed & Fish oil \\
\hline C14:0 & 0.06 & 5.91 \\
C16:0 & 5.53 & 17.1 \\
C16:1 & 0.08 & 7.26 \\
C18:0 & 3.56 & 4.29 \\
C18:1n-9 cis & 16.29 & 17.46 \\
C18:2n-6 cis-9, cis-12 & 16.75 & 6.4 \\
C18:3n-3 (docosahexaenoic acid) & 53.21 & 1.17 \\
C20:5n-3 & 0.01 & 6.15 \\
C22:6n-3 (eicosapentaenoic acid) & 0.01 & 6.72 \\
\hline
\end{tabular}


thickness, was calculated from the 2 measurements made with calipers as the difference between 24-h postinjection thickness and preinjection thickness.

\section{Establishment of Humoral Response to a Nominal Antigen Chicken Egg Albumin}

At the start of the experiment (d 0), $2 \mathrm{mg}$ of chicken egg albumin (OVA; Sigma) dissolved in $1 \mathrm{~mL}$ of sterile saline solution and $1 \mathrm{~mL}$ of incomplete Freund's adjuvant (Sigma) was injected subcutaneously into both shoulders of each cow. A subsequent injection of $2 \mathrm{mg}$ of OVA in saline without adjuvant was administered 15 d later.

\section{Sampling of Blood for the Preparation of Plasma}

Blood was taken from the caudal vein from each cow at $\mathrm{d} 0,15,30,45,60,75$, and 90 of the experiment. Samples were collected into duplicate heparinized vacuum tubes (Becton Dickinson, Plymouth, UK) for each animal. Blood samples were centrifuged at 1,200 $\times g$ for $15 \mathrm{~min}$ at $25^{\circ} \mathrm{C}$ to separate plasma from the corpusculate fraction. Plasma samples were collected and aliquoted in 6 replicates for each animal, and then stored at $-80^{\circ} \mathrm{C}$, until used to perform ELISA to evaluate the anti-OVA IgG titers and IL-1 $\beta$, IL-6, and IL-10 concentrations.

\section{Anti-OVA Specific IgG ELISA}

The anti-OVA antibody titer in cow plasma samples was evaluated by an ELISA test performed in 96-well U-bottomed microtiter plates according to Caroprese et al. (2006). Wells were coated with $100 \mu \mathrm{L}$ of antigen $(10 \mathrm{mg}$ of $\mathrm{OVA} / \mathrm{mL}$ of $\mathrm{PBS})$ at $4^{\circ} \mathrm{C}$ for $12 \mathrm{~h}$, washed, and incubated with $1 \%$ skimmed milk $(200 \mu \mathrm{L})$ at $37^{\circ} \mathrm{C}$ for $1 \mathrm{~h}$ to reduce nonspecific binding. After washing, the plasma (1:5,000 dilution in PBS; $100 \mu \mathrm{L}$ per well) was added and incubated at $37^{\circ} \mathrm{C}$ for $1 \mathrm{~h}$. The extent of antibody binding was detected using a horseradish peroxidase-conjugated donkey anti-bovine IgG (Sigma; 1:20,000 dilution in PBS; $100 \mu \mathrm{L}$ per well). Optical density was measured at a wavelength of $450 \mathrm{~nm}$. Plasma samples were read against a standard curve obtained using scalar dilution of bovine IgG (Sigma). Data were expressed as milligrams of anti-OVA IgG per milliliter. The inter- and intraassay coefficients of variation were 3.6 and $4.5 \%$, respectively.

\section{Determination of IL-1 $\beta$, IL-6, and IL-10 Production by ELISA}

The detection of IL-6 and IL-1 $\beta$ in plasma was determined by capture ELISA performed on 96-well microtiter plates (Caroprese et al., 2006) with some modifications. Mouse monoclonal antibodies specific for bovine IL-6 and for ovine IL-1 $\beta(100 \mu \mathrm{L}, 5 \mu \mathrm{g} / \mathrm{mL}$; Serotec Ltd., Kidlington, UK) dissolved in $50 \mathrm{~m} M$ carbonate buffer (pH 9.6) were used to coat wells and incubated overnight at $4^{\circ} \mathrm{C}$. After washing with PBS $(\mathrm{pH} 7.2)$ and $0.05 \%$ Tween 20 (PBST), plates were incubated with $100 \mu \mathrm{L}$ of $3 \%$ BSA diluted in PBST at room temperature for 1 $\mathrm{h}$ to block nonspecific binding. Plates were then washed 2 times with PBST and the plasma $(50 \mu \mathrm{L}$ per well $)$ was added and incubated at room temperature for $1 \mathrm{~h}$ and 30 min. Buffer alone or 3\% BSA in PBST provided negative control wells. Rabbit polyclonal antibody antiovine IL-6 and anti-bovine IL-1 $\beta$ conjugated to biotin (Serotec Ltd.) were used as detecting antibodies (1:500 diluted in 3\% BSA in PBST) to determine captured IL- 6 and IL-1 $\beta$ and incubated at room temperature for $1 \mathrm{~h}$ and $30 \mathrm{~min}$. The presence of IL- 6 was detected using goat anti-rabbit IgG conjugated to horseradish peroxidase (Sigma Aldrich). After a further washing, $100 \mu \mathrm{L}$ of substrate consisting of tetra methyl benzidine free base tablets (Sigma Aldrich), dimethyl sulfoxide (Sigma Aldrich), dissolved in $0.05 M$ phosphate-citrate buffer ( $\mathrm{pH}$ 5.0), and $\mathrm{H}_{2} \mathrm{O}_{2}$ was added to each well and incubated for $30 \mathrm{~min}$ at $37^{\circ} \mathrm{C}$. Finally, $2 \mathrm{M} \mathrm{H}_{2} \mathrm{SO}_{4}$ was added to terminate reactions. Concentrations of IL-1 $\beta$ were detected using streptavidin conjugated to horseradish peroxidase. The substrate used was the same as for detection of IL-6. The following steps were carried out as described above for the anti-OVA IgG detection. Plasma samples were read against a standard curve obtained using scalar dilution of bovine IL-1 $\beta$ (Serotec Ltd.). Data were expressed as nanograms of IL-1 $\beta$ per milliliter. Data for IL-6 were expressed as relative optical densities because of the lack of availability of a recombinant bovine IL-6 standard.

Production of IL-10 was determined using a pair of bovine-specific monoclonal antibodies against IL-10 (Serotec Ltd.) in a sandwich capture ELISA described in detail by Kwong et al. (2002). The ELISA was standardized using biologically active recombinant ovine IL-10 expressed in Chinese hamster ovary cells using the glutamine synthase (GS) expression vector (Lonza, Berkshire, UK). Production of recombinant ruminant cytokines using this system has been described in detail elsewhere (Graham et al., 1995; Entrican et al., 1996). Recombinant ovine IL-10 was provided by the Biotechnology and Biological Sciences Research Council/Rural and Environment Research and Analysis Directorate (BBSRC/RERAD) Immunological Toolbox. The ELISA standards were prepared by doubling dilutions of IL-10 from 3.645 bio-units $/ \mathrm{mL}$ to 0.043 bio-units $/ \mathrm{mL}$ to generate a standard curve $(\mathrm{y}=-0.007271+0.0994 \mathrm{x}$ $\left.+0.0065 \mathrm{x}^{2} ; \mathrm{R}^{2}=99.09 \%\right)$. 


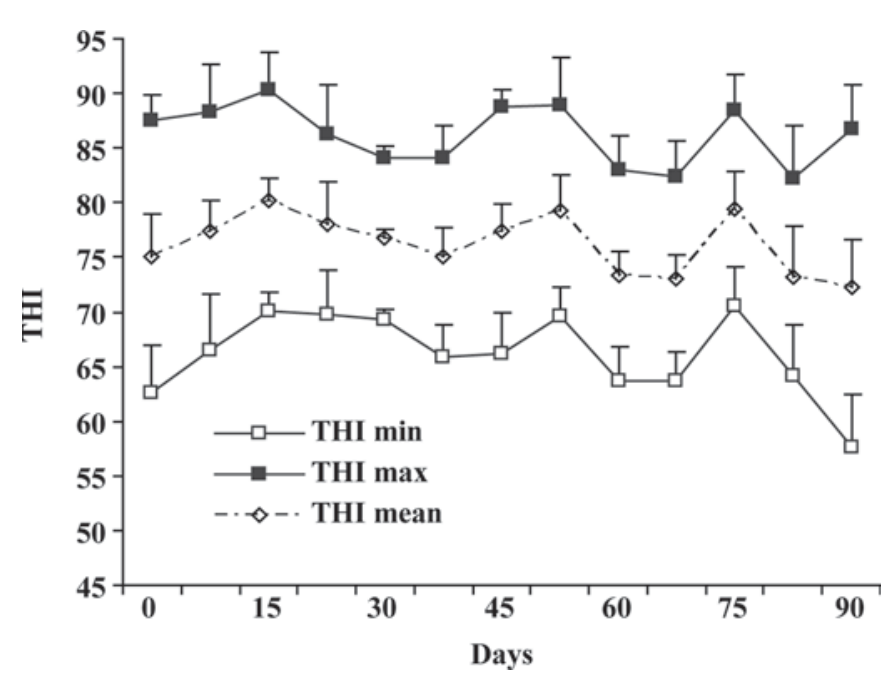

Figure 1. Weekly averages of temperature-humidity index (THI) values (minimum, maximum, and mean) detected during the days of the experimental period, calculated using Kelly and Bond's (1971) formula.

\section{Statistical Analysis}

All variables were tested for normality using the Shapiro-Wilk test (Shapiro and Wilk, 1965) and transformed in logarithm form to normalize their frequency distribution, when necessary. Then, data were processed by ANOVA, using the GLM procedure for repeated measures (SAS Institute, 1999). The model utilized was $\mathrm{y}_{\mathrm{ijkl}}=\mu+\alpha_{\mathrm{i}}+\beta_{\mathrm{ij}}+\gamma_{\mathrm{k}}+(\alpha \gamma)_{\mathrm{ik}}+\varepsilon_{\mathrm{ijk} \mathrm{k}}$, where $\mu=$ the overall mean; $\alpha=$ feeding treatment, $\beta$ $=$ animal effect within feeding treatment; $\gamma=$ day of sampling effect; $\alpha \gamma=$ interaction of feeding treatment $\times$ day of sampling; and $\varepsilon=$ error. Block effects were not significant for the variables tested; thus, block was not used as source of variation in the statistical model. For humoral response, antibody titers measured at the beginning of the experiments were used as covariates. When significant effects were found (at $P<0.05$ ), Student's $t$-test was used to locate significant differences between means.

\section{RESULTS}

\section{Meteorological Data}

Air temperature and relative humidity measured during the study period were expressed as THI (Figure $1)$. During the experiment, weekly averages of mean THI were always $>72$, which is regarded as the upper critical limit for THI for dairy cows. At d 15, 45, and 75 , mean daily THI reached the highest values, and maximum THI exceeded 88.

\section{Cell-Mediated Response}

On average, cows fed FS displayed higher skin-fold thickness lymphocyte proliferation after PHA challenge $\left(0.56 \log _{10} \mathrm{~mm}, P<0.05\right)$ compared with control group and cows fed FO (0.42 and $0.47 \log _{10} \mathrm{~mm}$, respectively; Figure 2). In particular, FS cows exhibited a higher skin-fold thickness than control cows both at 45 and $90 \mathrm{~d}$ and than FO cows at $45 \mathrm{~d}$ of the experiment $(P$ $<0.01)$. During the trial, skin-fold thickness did not change in FS cows and decreased in control cows and in FO cows $(P<0.05)$.

\section{Humoral Response}

Humoral response was significantly affected by feeding treatment $(P<0.001$; Figure 3$)$, with FS cows displaying higher mean IgG titers than control and FO cows. At $30 \mathrm{~d}$, and then at 45, 60, $75 \mathrm{~d}$ of the experiment, IgG concentrations were higher in cows fed FS than in cows of the control group. At $60 \mathrm{~d}$ of the experiment, cows fed FS showed higher IgG titers than cows fed FO. A time effect for IgG titers was also found $(P<0.001)$, because the anti-OVA IgG concentration was higher at 30,45 , and $60 \mathrm{~d}$ than at 15, 75, and $90 \mathrm{~d}$.

\section{Determination of IL-1 $\beta$, IL-6, and IL-10}

Results obtained from IL-1 $\beta$ assay showed no significant differences among groups, but a time effect was found $(P<0.001)$. Secretion of IL-1 $\beta$ in cows started to increase slightly from the beginning of the trial and at d 45 was different from the values recorded at $15 \mathrm{~d}$ and at the end of the experiment (Figure 4). Results obtained from IL-6 assay showed no significant differences among groups, although a time effect was found because a decrease of IL- 6 secretion at 15 and $30 \mathrm{~d}$ was recorded in all groups $(P<0.001$; Figure 5$)$. Secretion of IL-10 was lower in FS than in the control group ( 25.56 vs. $36.93 \pm 3.7 \mathrm{bU} / \mathrm{mL}, P<0.05$; Figure 6 ).

\section{DISCUSSION}

The present study aimed at evaluating the effects of feed supplementation with FO and FS to dairy cows on their immune functions under high ambient temperatures. A growing body of evidence suggests that dietary PUFA can modulate the composition and function of cells of the immune system by suppressing lymphocyte proliferation, natural killer cell activity, some macrophage functions, and the production of inflammatory cytokines by macrophages (Yaqoob and Calder, 1995). Polyunsaturated fatty acids administered as flaxseed to dairy cows maintained the levels of lymphocyte 


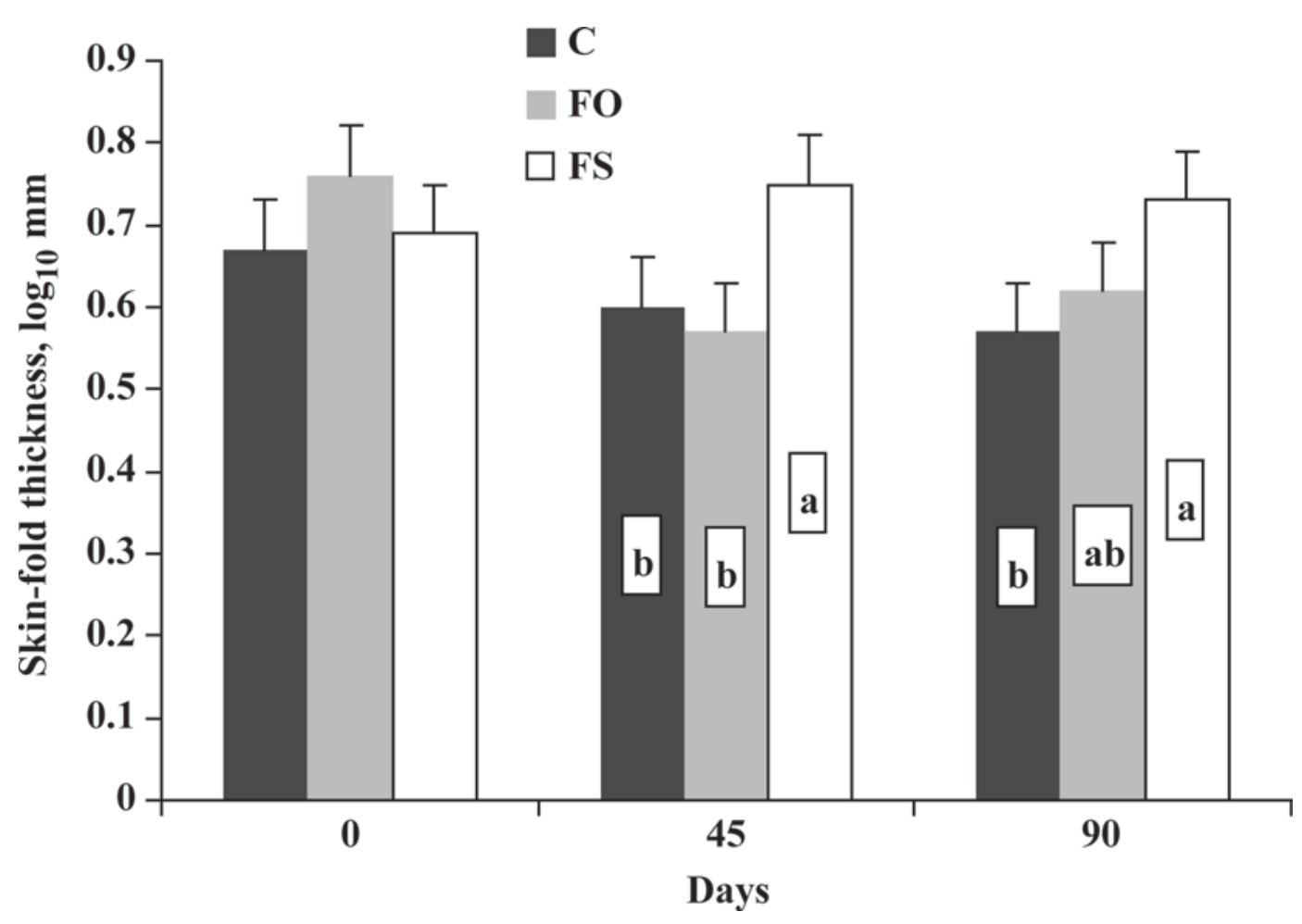

Figure 2. Skin-fold thickness (least squares means \pm SEM) after phytohemagglutinin injection detected in cows fed the control diet (C), fish oil (FO), or flaxseed (FS) at the beginning of the trial, and then at 45 and $90 \mathrm{~d}$ of the trial. ${ }^{\mathrm{a}, \mathrm{b}}$ Values with different letters differ between feeding treatments within a sampling day $(P<0.05)$.

proliferation under high ambient temperatures. In previous studies (Elvinger et al., 1991; Kamwanja et al., 1994; Lacetera et al., 2005), impairment of bovine lymphocyte function in cows in hot environments was reported. The reduced cellular immunity measured in dairy cows in hot environments can be explained by hyperthermia that can influence the T-helper (Th)1/ Th2 balance in favor of the secretion of Th2 cytokines, which are responsible for the impairment of lymphocyte proliferation (Murzenok et al., 1997; Lacetera et al., 2005). Dietary lipids, given as both linseed and fish oils, were noted to attenuate the alterations of lymphocyte proliferation in conditions of energy deficit (Lacetera et al., 2007). Although both experimental groups were supplemented with an n-3 PUFA diet, different trends in lymphocyte proliferation between FS and FO cows emerged. Indeed, FS but not FO supplementation helped cows to counteract heat load probably by opposing the lymphocyte shift from Th1 to Th2 type. The lower levels of IL-10 observed in FS cows support the hypothesis that flaxseed supplementation can contrast the secretion of Th2 cytokines in hot environments, thus helping cows to recover their immune functions. The suppressive role of IL-10 involves the inactivation of macrophages and dendritic cells, with a consequent inhibition of Th1-mediated responses, such as cellular immunity (Dinarello, 1996). Previous findings in vitro showed no effects of $\alpha$-linolenic acid (C18:3n-3) on bovine lymphocyte proliferation (Thanasak et al., 2005), or a reduced proliferative response of PBMC in cows fed flaxseed (Lessard et al., 2003). The absence of clear effects of fish oil supplementation on cow immune functions may be ascribed to 2 factors: first, it could be argued that the amounts of eicosapentaenoic acid (EPA) and docosahexaenoic acid (DHA) administered in the supplementation were insufficient to induce an evident improvement of the immune functions; second, rumen biohydrogenation of the FO might have occurred. In any case, administration of FO supplementation to dairy cows has been proved to be efficacious in enhancing EPA and DHA concentrations in milk (0.06 and 0.12 $\mathrm{g} / 100 \mathrm{~g}$ of fatty acids in milk of cows supplemented with $\mathrm{FO}$ vs. 0.003 and $0.001 \mathrm{~g} / 100 \mathrm{~g}$ of fatty acids in milk of nonsupplemented cows; M. Caroprese, A. Marzano, R. Marino, G. Gliatta, A. Muscio, and A. Sevi, Dipartimento PRIME, Università di Foggia, Foggia, Italy; unpublished data).

The hypothesis of the modulating effect of flaxseed on cow immune functions under hot ambient temperature was supported by the humoral response, because anti-OVA IgG concentrations were always higher in FS cows than in control cows. These findings contrast with 


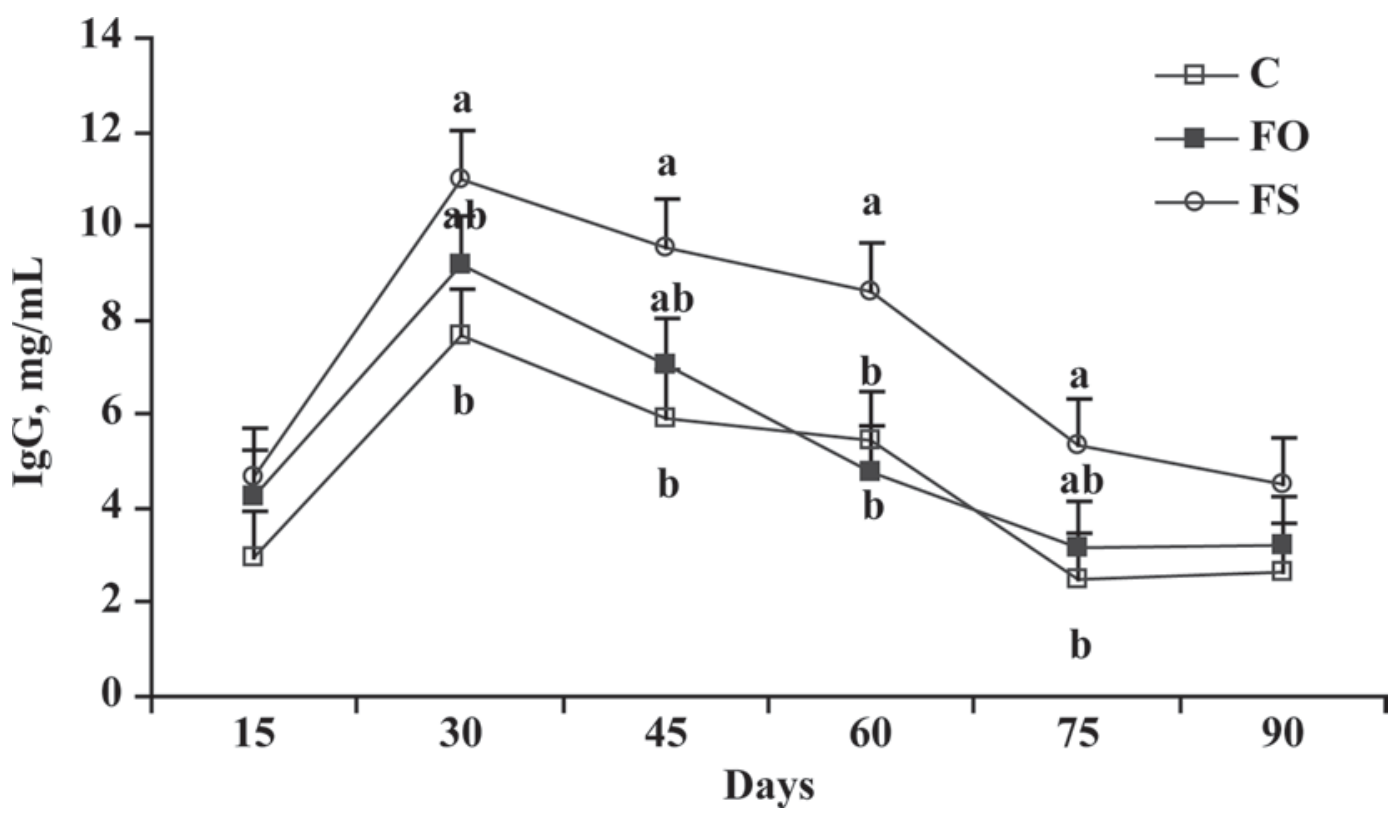

Figure 3. Antibody titers to chicken egg albumin (least squares means \pm SEM) detected in blood of cows fed the control diet (C), fish oil (FO), or flaxseed (FS) at d 15,30,45, 60, 75, and 90 of the trial. ${ }^{\mathrm{a}, \mathrm{b}}$ Values with different letters differ between feeding treatments within a sampling day $(P<0.05)$.

studies reporting no effects in humoral responses of cows to flaxseed supplementation (Lessard et al., 2003, 2004). Discrepancies among the experiments could be explained by differences in the physiological state of cows. We hypothesized that dietary lipids could lead to different effects on immune function in relation to different magnitude and nature of stress. The immunological state of the transition cow is influenced by homeorhetic mechanisms that are regulated by a complex hormonal system and are responsible for the physiologic changes

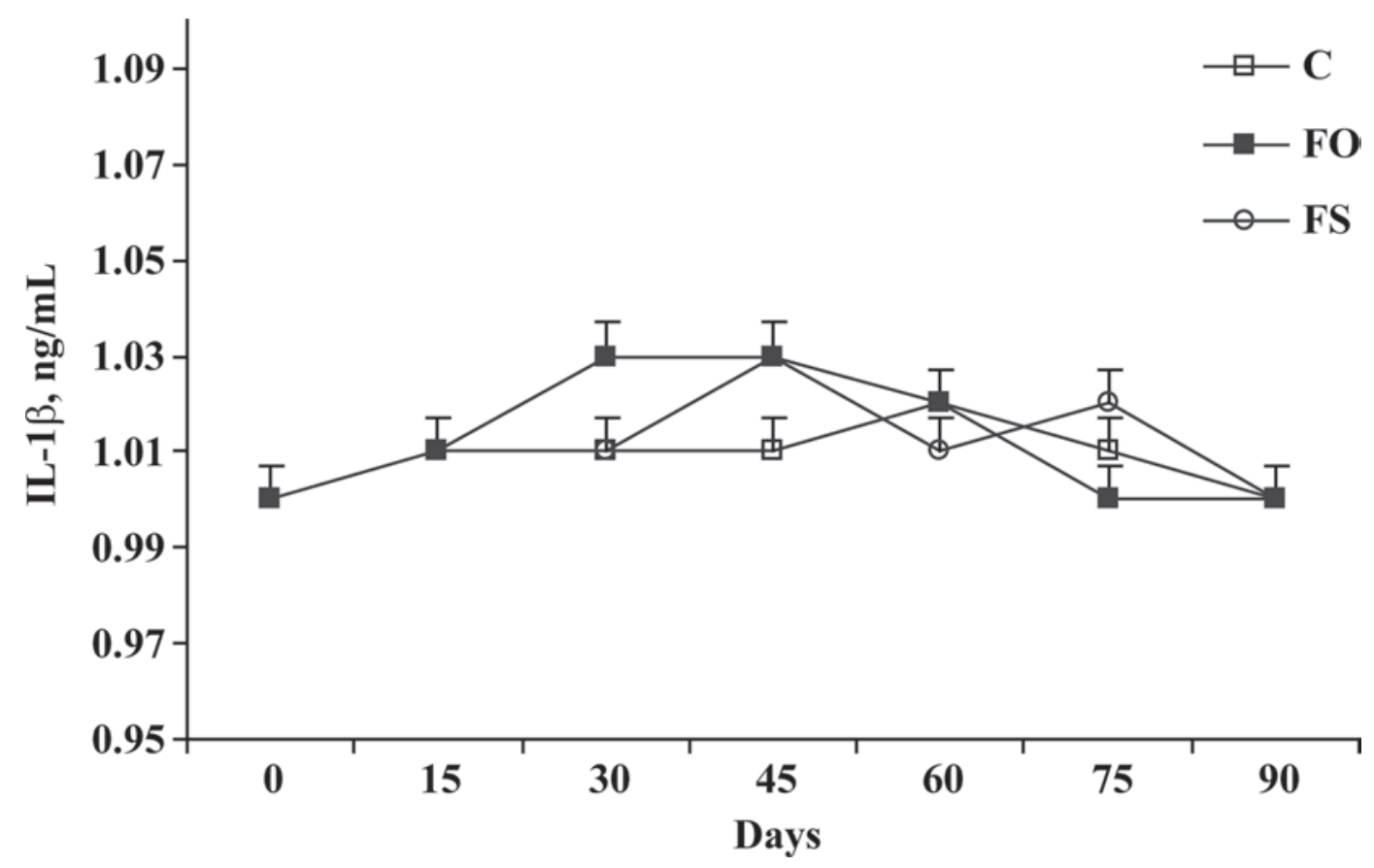

Figure 4. Interleukin-1 $\beta$ secretion (least squares means \pm SEM) detected in blood of cows fed the control diet (C), fish oil (FO), or flaxseed (FS) at d 0, 15, 30, 45, 60, 75, and 90 of the trial. 


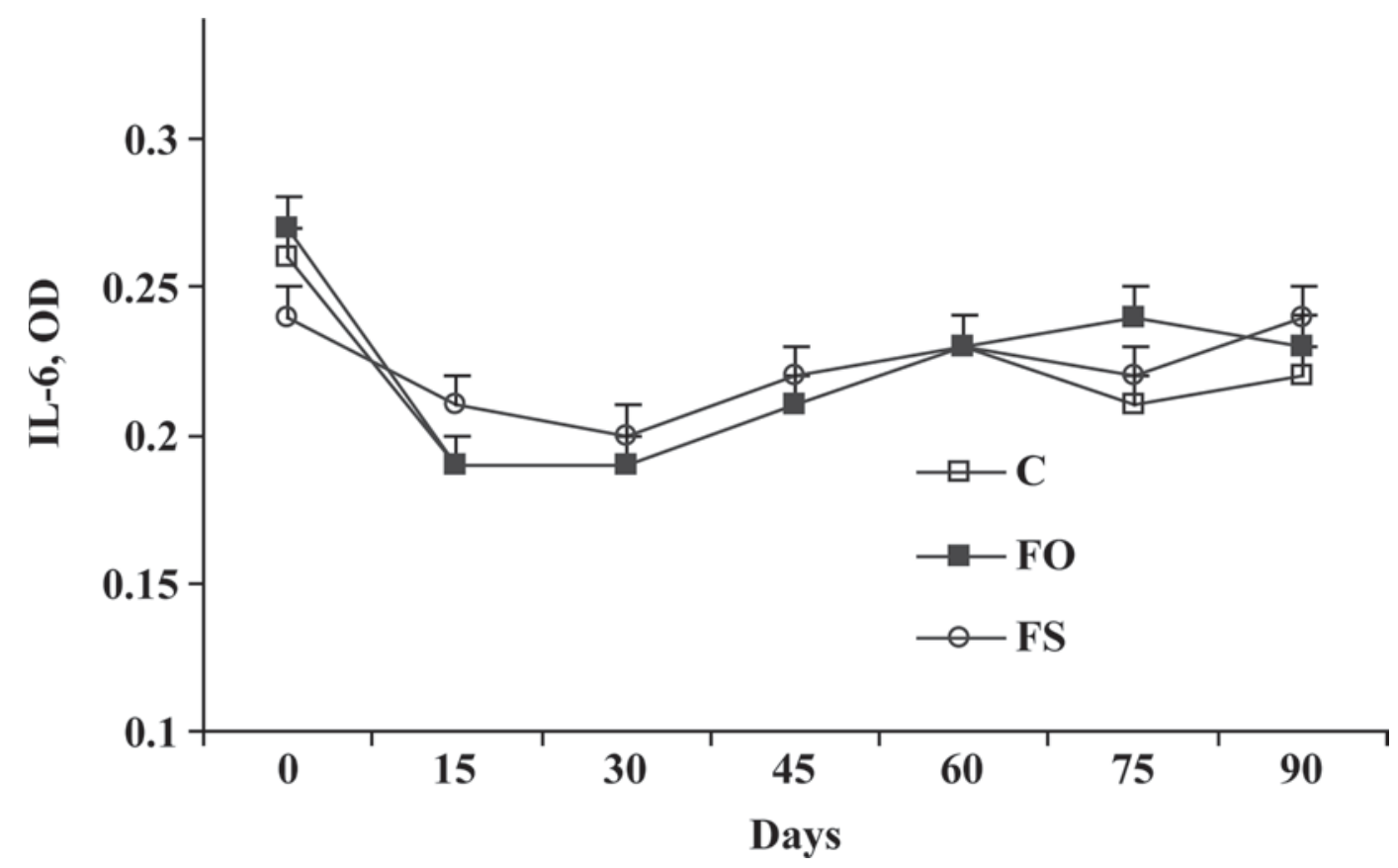

Figure 5. Interleukin-6 secretion (least squares means \pm SEM; measured as optical density; OD) detected in blood of cows fed the control diet (C), fish oil (FO), or flaxseed (FS) at d 0, 15, 30, 45, 60, 75, and 90 of the trial.

associated with parturition and the beginning of lactation (Overton and Waldron, 2004). The responses of cows to heat stress involve homeostatic pathways aimed at maintaining a constant body temperature. Bauman and Currie (1980) stated that physical and physiological challenges can generate different and sometimes conflicting coping mechanisms in animals, and that threats to maintenance of constant conditions in the internal environment (i.e., homeostasis) have a stronger effect on animals than metabolism changes evoked to support a physiological state (i.e., homeorhesis).

The absence of a diet effect on proinflammatory cytokine secretion could be ascribed to the tightly regulated gene expression, synthesis, and secretion of both IL-1 $\beta$ and IL-6 (Dinarello, 1996; McWaters et al., 2000). Data about the effects of long-chain n-3 PUFA on proinflammatory cytokines are conflicting (Calder, 2001). Human and animal studies have provided a great deal of evidence that feeding plant or fish oil rich in n-3 FA alters the production of cytokines and the functional properties of macrophages, lymphocytes, and other immunocompetent cells (Yaqoob and Calder, 1995; Calder, 2002). Fish oil feeding decreased production of TNF- $\alpha$, IL-1 $\beta$, and IL- 6 ex vivo by rodent macrophages, even if an effect of the amounts of EPA and DHA on proinflammatory and Th1-type cytokine secretions has been found (Meydani et al., 1991; Sasaki et al., 2000; Wallace et al., 2000). Another tentative explanation for the failure to find differences in cytokine secretion could be the complexity of in vivo systems compared with in vitro models. Moreover, in the current study, cows were subjected to high ambient temperatures, which could have partially hidden the effects of dietary lipids on cytokine secretion. In both mouse and human macrophages, an activation of the innate immune response resulting in enhanced secretion of pro-inflammatory cytokines, was found after exposure to human HSP60, a protein released during heat stress (Chen et al., 1999).

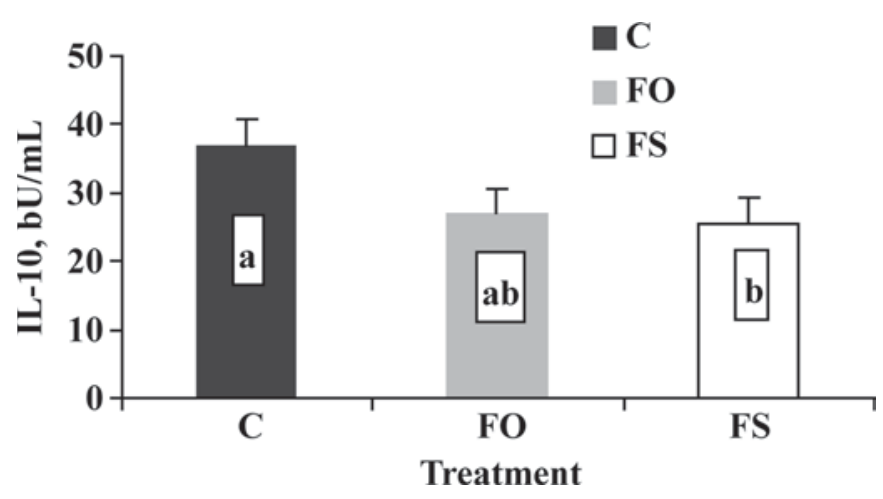

Figure 6. Interleukin-10 secretion (least squares means \pm SEM) detected in blood of cows fed the control diet (C), fish oil (FO), or flaxseed (FS) measured during the experimental period; bU = bio-units. ${ }^{\mathrm{a}, \mathrm{b}}$ Values with different letters differ between feeding treatments within a sampling day $(P<0.01)$. 


\section{CONCLUSIONS}

Supplementation with n-3 PUFA as whole flaxseed has immunomodulatory properties able to sustain cow immune functions under high ambient temperatures. Cows fed flaxseed exhibited an improvement of cellular immune reactivity to PHA, anti-OVA IgG concentration, and a reduction of IL-10 secretion. In contrast, fish oil supplementation did not seem to have effects on immune responses of cows in hot stress conditions. Irrespective of source, dietary fatty acids did not change secretion of proinflammatory cytokines.

\section{ACKNOWLEDGMENTS}

The authors thank Concetta Perilli and Stefano D'Urso (Dipartimento PRIME, Università di Foggia) for expert technical assistance. This work was conducted using recombinant ovine IL-10 generated within the BBSRC/RERAD Immunological Toolbox (grant numbers BBS/B/00255, MRI/094/04), provided by Gary Entrican and Sean Wattegedera at the Moredun Research Institute (Edinburgh, UK) and funded by the Scottish Government Rural and Environment Research and Analysis Directorate.

\section{REFERENCES}

AOAC. 1990. Official Methods of Analysis. 15th ed. AOAC, Arlington, VA.

Bauman, D. E., and W. B. Currie. 1980. Partitioning of nutrients during pregnancy and lactation: A review of mechanisms involving homeostasis and homeorhesis. J. Dairy Sci. 63:1514-1529.

Calder, P. C. 2001. n-3 Polyunsaturated fatty acids, inflammation and immunity: Pouring oil on troubled waters or another fishy tale? Nutr. Res. 21:309-341.

Calder, P. C. 2002. Dietary modification of inflammation with lipids. Proc. Nutr. Soc. 61:345-358.

Caroprese, M., M. Albenzio, G. Annicchiarico, and A. Sevi. 2006. Changes occurring in immune responsiveness of single- and twinbearing Comisana ewes during the transition period. J. Dairy Sci. 89:562-568.

Chen, W., U. Syldath, K. Bellman, V. Burkart, and H. Kolb. 1999. Human $60 \mathrm{kDa}$ heat-shock protein: a danger signal to the innate immune system. J. Immunol. 162:3212-3219.

Dinarello, C. A. 1996. Biological basis for interleukin-1 in disease. J. Am. Soc. Hematol. 87:2095-2147.

Elvinger, F., P. J. Hansen, and R. P. Natzke. 1991. Modulation of function of bovine polimorphonuclear leukocytes and lymphocytes by high temperature in vitro and in vivo. Am. J. Vet. Res. 52:1692-1698.

Entrican, G., D. Deane, M. MacLean, L. Inglis, J. Thomson, C. McInnes, and D. M. Haig. 1996. Development of a sandwich ELISA for ovine granulocyte/macrophage colony-stimulating factor. Vet. Immunol. Immunopathol. 50:105-115.

Graham, S. P., G. E. Jones, M. MacLean, M. Livingstone, and G. Entrican. 1995. Recombinant ovine interferon gamma inhibits the multiplication of Chlamydia psittaci in ovine cells. J. Comp. Pathol. 112:185-195.
Kamwanja, L. A., C. C. Chase, J. A. Gutierrez, V. Guerriero, T. A. Olson, A. C. Hammond, and P. J. Hansen. 1994. Responses of bovine lymphocytes to heat shock as modified by breed and antioxidant status. J. Anim. Sci. 72:438-444.

Kelley, D. S. 2001. Modulation of human immune and inflammatory responses by dietary fatty acids. Nutrition 17:669-673.

Kelly, C. F., and T. E. Bond. 1971. Bioclimatic factors and their measurement. A guide to environmental research on animals. National Academy Press, Washington, DC.

Kwong, L. S., J. C. Hope, M. L. Thom, P. Sopp, S. Duggan, G. P. Bembridge, and C. J. Howard. 2002. Development of an ELISA for bovine IL-10. Vet. Immunol. Immunopathol. 85:213-223.

Lacetera, N., U. Bernabucci, D. Scalia, B. Ronchi, G. Kuzminsky, and A. Nardone. 2005. Lymphocyte functions in dairy cows in hot environment. Int. J. Biometeorol. 50:105-110.

Lacetera, N., D. Scalia, B. Ronchi, D. G. Mashek, U. Bernabucci, and R. R. Grummer. 2007. Effects of intravenous triacylglycerol emulsions on lymphocyte responses to mitogens in fasted dairy cows undergoing intense lipomobilization. J. Dairy Res. 74:323328.

Lessard, M., N. Gagnon, L. Godson, and H. V. Petit. 2004. Influence of parturition and diets enriched in n-3 or n- 6 Polyunsaturated fatty acids on immune response of dairy cows during the transition period. J. Dairy Sci. 87:2197-2210.

Lessard, M., N. Gagnon, and H. V. Petit. 2003. Immune response of postpartum dairy cows fed flaxseed. J. Dairy Sci. 86:2647-2657.

McWaters, P., L. Hurst, P. J. Chaplin, R. A. Collins, P. R. Wood, and J. P. Y. Scheerlinck. 2000. Characterization of monoclonal antibodies to ovine interleukin-6 and the development of a sensitive capture ELISA. Vet. Immunol. Immunopathol. 73:155-165.

Meydani, S. N., S. Endres, M. M. Woods, B. R. Goldin, C. Soo, A Morrill-Labrode, C. A. Dinarello, and S. L. Gorbach. 1991. Oral $(n-3)$ fatty acid supplementation suppresses cytokine production and lymphocyte proliferation: Comparison between young and older women. J. Nutr. 121:547-555.

Murzenok, P. P., N. I. Netukova, and T. I. Zhytkevitch. 1997. Ultrastructure and functional state of rabbit lymphoid cells after repeated exposure to lipopolysaccharide and external heating. Arch. Immunol. Ther. Exp. (Warsz.) 45:301-305.

NRC. 2001. Nutrient Requirements of Dairy Cattle. 7th rev. ed. Natl. Acad. Sci., Washington, DC.

Overton, T. R., and M. R. Waldron. 2004. Nutritional management of transition dairy cows: Strategies to optimize metabolic health. J. Dairy Sci. 87(E Suppl.):E105-E119.

SAS Institute. 1999. SAS User's Guide: Statistics. Version 8.1 ed. SAS Inst. Inc., Cary, NC.

Sasaki, T., Y. Kanke, K. Kudoh, M. Nagahahsi, M. Toyokawa, M. Matsuda, J. Shimizu, and T. Takita. 2000. Dietary n-3 polyunsaturated fatty acid and status of immuno-competent cells involved in innate immunity in female rats. Ann. Nutr. Metab. 44:38-42

Shapiro, S. S., and M. B. Wilk. 1965. An analysis of variance test for normality. Biometrika 52:591-601.

Sukhija, P. S., and D. L. Palmquist. 1988. Rapid method for determination of total fatty acid content and composition of feedstuffs and feces. J. Agric. Food Chem. 36:1202-1206.

Thanasak, J., K. E. Mullerb, S. J. Dielemana, A. Hoekd, J. P. T. M. Noordhuizena, and V. P. M. G. Ruttend. 2005. Effects of polyunsaturated fatty acids on the proliferation of mitogen stimulated bovine peripheral blood mononuclear cells. Vet. Immunol. Immunopathol. 104:289-295.

Wallace, F. A., E. A. Miles, and P. C. Calder. 2000. Activation state alters the effect of dietary lipids on pro-inflammatory mediator production by murine macrophages. Cytokine 12:1374-1379.

Yaqoob, P., and P. C. Calder. 1995. The effect of dietary lipid manipulation on the production of murine T-cell-derived cytokines. Cytokine 7:548-553. 